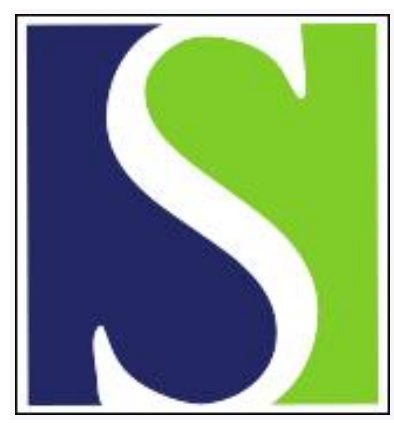

Scand J Work Environ Health 2002;28(1):25-32

https://doi.org/10.5271/sjweh.643

Issue date: Feb 2002

Physical workload and the risk of severe knee osteoarthritis

by Manninen P, Heliövaara M, Riihimäki $H$, Suomalainen $O$

Affiliation: Kuopio Regional Institute of Occupational Health, PO Box 93, Fl-70701 Kuopio, Finland. pirjo.manninen@tt.fi

Refers to the following texts of the Journal: 1996;22(3):165-175 2000;26(1):20-25

The following articles refer to this text: 2003;29(4):304-313;

2004;30(4):261-278; 2007;33(6):405-424; 2015;41(2):124-139

Key terms: case-referent study; community study; heavy work; knee arthroplasty; knee osteoarthritis; physical workload; risk

This article in PubMed: www.ncbi.nlm.nih.gov/pubmed/11871849 


\title{
Physical workload and the risk of severe knee osteoarthritis
}

\author{
by Pirjo Manninen, DrMedSc, ${ }^{1}$ Markku Heliövaara, DrMedSc, ${ }^{2}$ Hilkka Riihimäki, DrMedSc, ${ }^{3}$ Olavi Suoma- \\ lainen, DrMedSc ${ }^{4}$
}

\begin{abstract}
Manninen P, Heliövaara M, Riihimäki H, Suomalainen 0. Physical workload and the risk of severe knee osteoarthritis. Scand J Work Environ Health 2002;28(1):25-32.

Objectives This study investigated the impact of physical workload on the risk of severe knee osteoarthritis (OA) leading to knee arthroplasty.

Methods In this case-referent study, the cases were 55- to 75-year-old men $(\mathrm{N}=55)$ and women $(\mathrm{N}=226)$ who had undergone their first knee arthroplasty operation for primary knee OA in the Kuopio University Hospital in 1992-1993. The referents $(\mathrm{N}=524)$ were from the same source population and were matched with the cases for age and gender. Information on explanatory variables was obtained by a computer-assisted telephone interview. Exposure was assessed up to 49 years of age.

Results After adjustment for body mass index, knee injury and leisure-time physical activity, an increased relative risk of knee OA was found for a history of high physical workload. The odds ratio (OR) was 1.53 [95\% confidence interval (95\% CI) 0.42-5.56] for the men and 2.03 (95\% CI 1.03-3.99) for the women as compared with those with low physical workload. With respect to generic risk factors, climbing already at a medium level of exposure was associated with an increased risk of knee OA among the men (OR 3.06, 95\% CI 1.25-7.46) and kneeling and squatting was a risk factor for both genders. Of the different trades, agriculture, forestry, fishing, transportation, and traffic showed the highest risks of knee OA.

Conclusions The results of this study agree with the hypotheses that heavy physical loading increases the risk of knee OA and that cumulative physical stress has a deleterious effect on the knee joint.
\end{abstract}

Key terms case-referent study, community study, heavy work, knee arthroplasty.

Knee osteoarthritis (OA) is an important cause of pain and disability in later life. The etiology of knee OA is multifactorial, and the following risk factors have been identified: heredity (1-3), obesity $(1,4-10)$, injury (1, $7-8,11-12)$ and physical loading (5, 11-24). Physical loading can be attributed to either occupational or recreational activities or both.

An increased work-related risk of knee OA has been revealed in two classical studies, both dating from almost 50 years ago (25-26). Subsequent knowledge on the effect of occupational loading on the knee joint has accumulated slowly. One difficulty is the measurement of occupational exposure. Three reviews have considered the role of occupational risk factors for knee OA (11, 19-20). In most studies included in these reviews job description or title has been used as an indicator of workload, and generic exposures have not been assessed separately.

Epidemiologic studies investigating occupational risk factors of osteoarthritis should focus on a more accurate assessment of exposure. Thus far, only a few studies on knee OA have considered the effects of generic work-related risk factors $(8,12,14,21-24)$. This case-referent study was conducted to investigate the associations between occupational exposures and the risk of severe knee OA.

\section{Subjects and methods}

The source population comprised all 55- to 75-year-old inhabitants living in the Kuopio Province of Finland.

1 Department of Public Health and General Practice, University of Kuopio, Kuopio Regional Institute of Occupational Health, Kuopio, Finland.

2 National Public Health Institute, Helsinki, Finland.

3 Department of Epidemiology and Biostatistics, Finnish Institute of Occupational Health, Helsinki, Finland.

4 Department of Surgery, Kuopio University Hospital, Kuopio, Finland.

Reprint requests to: Manninen Pirjo, Kuopio Regional Institute of Occupational Health, PO Box 93, FIN-70701 Kuopio, Finland. [E-mail: pirjo.manninen@ttl.fi] 
The cases were all the men and women who had undergone their first knee arthroplasty operation for primary osteoarthritis in the Kuopio University Hospital in 1992 and 1993. The cases were identified through the Finnish Registry of Arthroplasties (27). The referents were a random sample of the source population matched with the cases for age $( \pm 2.5$ years) and gender.

Altogether 1157 subjects, 358 cases and 799 referents, were invited to participate in the study. Sixty-one cases (17\%) and 239 referents $(30 \%)$ could not be interviewed for the reasons shown in table 1. Altogether 4 male cases, 7 male referents, 13 female cases, and 28 female referents were excluded from the study, because they had cerebral palsy, rheumatoid arthritis or a lowextremity disease that was suspected to have been a potential reason for secondary knee OA (table 1). Thus 55 male cases (82\%), 226 female cases (78\%), 140 male referents $(67 \%)$ and 384 female referents $(65 \%)$ were included in the final analyses. The mean age was 67.5 (SD 5.7) years for the male cases, 67.2 (SD 5.6) years for the male referents, 69.2 (SD 5.4) years for the female cases, and 67.1 (SD 5.6) years for the female referents.

The subjects were interviewed in 1994 using a computer-assisted telephone interviewing system (28). They were asked about their history of chronic diseases, malformations in the lower extremities, knee injuries, recreational physical exercise, body weight and height, and smoking habits. Knee injuries were restricted to injuries that had led to a physician's consultation before the age of 49 years. For those who reported a history of regular recreational physical exercise, the exercise hours before the age of 49 years were calculated and divided into two classes according to the mean; those who had never exercised regularly were used as the reference. Body mass index (BMI, $\mathrm{kg} / \mathrm{m}^{2}$ ) was used as the measure of relative weight. In the analyses BMI at the age of 40 years was used. The mean BMI was 25.7 (SD 3.0) for the male cases, 24.9 (SD 2.9) for the male referents and 25.2 (SD 3.8) for the female cases and 23.9 (SD 3.2) for the female referents.

Work history was requested retrospectively in detail, and exposure to physical load factors in each job was inquired about separately. Only exposures before the age of 49 years were considered.

The assessment of exposures to physical workload, standing, climbing, kneeling, and squatting was based on occupation at the age of 49 years. Physical workload was classified as high, medium, or low according to the occurrence of sweating and rapid heartbeat (frequently = high, occasionally = medium, or not at all = low). For the assessment of standing at work, the subjects were asked how long they had to stand during an average workday. The choices were less than half of the day (low level), more than half of the day (medium level), and almost all the time (high level). In the assessment of exposure to kneeling or squatting during an average workday, the choices were "not at all", "less than 2 hours", "from 2 to 4 hours", and "more than 4 hours" a day. For the data analyses the exposure was classified as low (not at all), medium ( $<2$ hours), or high $(\geq 2$ hours). Accordingly, exposure to climbing was classified as low (not at all or very little), medium (some), or high (much).

For walking, lifting, and driving, cumulative exposure up to the age of 49 years was calculated. For walking the subjects were asked to estimate the average distance per week they had walked at work in each occupation. The weekly walking distance was multiplied by the number of workweeks per year and the number of years. The sum score based on the cumulative walking distances in each occupation was divided into the tertiles of low $(<2339 \mathrm{~km})$, medium $(2340-4971 \mathrm{~km})$, and high $(>4971 \mathrm{~km})$. Those with no regular walking at work were included in the low exposure category.

For an estimate of cumulative lifting, the subjects were asked, for each occupation separately, whether they had to do regular lifting at work. Thereafter they

Table 1. Participation in the study.

\begin{tabular}{|c|c|c|c|c|c|c|c|c|c|c|c|c|}
\hline & \multicolumn{4}{|c|}{ Men } & \multicolumn{4}{|c|}{ Women } & \multicolumn{4}{|c|}{ All } \\
\hline & \multicolumn{2}{|c|}{ Cases } & \multicolumn{2}{|c|}{ Referents } & \multicolumn{2}{|c|}{ Cases } & \multicolumn{2}{|c|}{ Referents } & \multicolumn{2}{|c|}{ Cases } & \multicolumn{2}{|c|}{ Referents } \\
\hline & $\mathrm{N}$ & $\%$ & $\mathrm{~N}$ & $\%$ & $\mathrm{~N}$ & $\%$ & $\mathrm{~N}$ & $\%$ & $\mathrm{~N}$ & $\%$ & $\mathrm{~N}$ & $\%$ \\
\hline Invited subjects & 67 & . & 208 & . & 291 & . & 591 & . & 358 & $\cdot$ & 799 & . \\
\hline \multicolumn{13}{|l|}{ Not interviewed } \\
\hline No telephone number or not reached by telephone & 4 & 5.9 & 48 & 23.0 & 42 & 14.4 & 131 & 22.2 & 46 & 12.8 & 179 & 22.4 \\
\hline Too ill to answer or dead & 1 & 1.5 & 5 & 2.4 & 3 & 1.0 & 17 & 2.8 & 4 & 1.1 & 22 & 2.7 \\
\hline Refusal or unreliable interview & 1 & 1.5 & 8 & 3.8 & 6 & 2.0 & 26 & 4.3 & 8 & 2.2 & 33 & 4.1 \\
\hline Reason unknown & 2 & 3.0 & - & $\cdot$ & 1 & 0.3 & 5 & 0.8 & 3 & 0.8 & 5 & 0.6 \\
\hline Secondary osteoarthritis & 4 & 5.9 & 7 & 3.3 & 13 & 4.4 & 28 & 4.7 & 17 & 4.7 & 35 & 4.3 \\
\hline Participating subjects & 55 & 82.0 & 140 & 67.3 & 226 & 77.6 & 384 & 64.9 & 281 & 78.4 & 524 & 65.5 \\
\hline
\end{tabular}


were asked to estimate the mean weight of the lifted objects and the number of lifts performed during an average workday. The sum score based on the cumulative lifted kilograms in each occupation was divided into two classes according to the mean. The exposure was classified into the following three categories: low (no regular lifting), medium ( $<100000 \mathrm{~kg})$, and high $(\geq 100000$ $\mathrm{kg}$ ). The cumulative hours of driving a motor vehicle were estimated in a manner similar to that used for walking and lifting. Exposure to driving was classified as low (no regular driving), medium $(<7000$ hours $)$, or high ( $\geq 7000$ hours).

Job title was also used as an explanatory variable for the risk of knee OA. The last job at the age of 49 years was classified into the following seven trade categories according to the classification of Statistics Finland: (i) technical, scientific, juridical, humanistic, artistic work, administrative and office work (white-collar worker), (ii) health care and social work, (iii) commercial work, (iv) agriculture, fishing and forestry, (v) transportation and traffic, (vi) manufacturing, mining and construction, and (vii) services (including housewives).

The data were analyzed with logistic regression modeling (29) producing odds ratios (OR) and 95\% confidence intervals $(95 \% \mathrm{CI})$. Each occupational exposure was tested separately in the multivariate analyses, in which BMI, knee injury, and leisure-time physical exercise were entered as potential confounding or effectmodifying variables. The statistical significance of the covariate terms was tested with the likelihood ratio test and expressed as exact P-values.

\section{Results}

The average number of years in the last job was 29.1 (SD 13.4) for the male cases and 30.7 (SD 11.6) for the male referents, the corresponding figures for the women being 27.4 (SD 14.2) and 26.1 (SD 13.7) years, respectively. Of the men and women $49 \%$ and $54 \%$, respectively, had been working in only one job during their career. The men had been, on the average, 6.2 (SD 9.6) years and the women 5.5 (SD 9.3) years in their second last job. Only $17 \%$ of the men and $15 \%$ of the women had had at least three jobs.

Of the potential confounders, history of knee injury and BMI were positively associated with the risk of knee $\mathrm{OA}$, whereas physical exercise during leisure time showed a negative association (table 2 ).

In the bivariate analyses (table 3 ), when the risk of knee OA was considered at different exposure levels, high physical workload seemed to increase the risk of knee OA for both genders. Of the generic occupational exposures, climbing and kneeling showed a positive association with knee OA. On the contrary, standing seemed to have a protective effect.

After adjustment for the potential confounding factors, a history of high physical workload seemed to increase the risk of knee OA twofold for both genders (table 4). The negative association between standing and the risk of knee OA could be discerned also in the adjusted analyses. The men who had to stand a lot at work had a $60 \%$ lower risk of knee OA than the men in sedentary work. Instead, walking showed no protection against knee OA. Kneeling and squatting seemed to increase the risk of knee OA. Climbing already at a medium exposure level was observed to increase the risk of knee OA among the men (OR 3.06, 95\% CI 1.257.46). There was a statistically significant $(\mathrm{P}=0.037)$ trend between cumulative history of driving and the risk of knee OA for the men and women combined; the adjusted odds ratio per each 10000 workhours was 1.02 (95\% CI 1.00-1.12). Lifting showed no association with the risk of knee $\mathrm{OA}$.

Table 2. Bivariate relative risks of severe knee osteoarthritis - logistic regression modeling. $(\mathrm{OR}=$ odds ratio, $95 \% \mathrm{Cl}=95 \%$ confidence interval)

\begin{tabular}{|c|c|c|c|c|c|c|c|c|c|c|c|c|}
\hline & \multicolumn{4}{|c|}{ Men } & \multicolumn{4}{|c|}{ Women } & \multicolumn{4}{|c|}{ All } \\
\hline & $\begin{array}{r}\text { Cases } \\
(\mathrm{N}=55)\end{array}$ & $\begin{array}{c}\text { Referents } \\
(\mathrm{N}=140)\end{array}$ & $\mathrm{OR}$ & $95 \% \mathrm{Cl}$ & $\begin{array}{c}\text { Cases } \\
(\mathrm{N}=226)\end{array}$ & $\begin{array}{c}\text { Referents } \\
(\mathrm{N}=384)\end{array}$ & $\mathrm{OR}$ & $95 \% \mathrm{Cl}$ & $\begin{array}{c}\text { Cases } \\
(\mathrm{N}=281)\end{array}$ & $\begin{array}{c}\text { Referents } \\
(\mathrm{N}=524)\end{array}$ & OR & $95 \%$ Cl \\
\hline Body mass index ${ }^{a}\left(\mathrm{~kg} / \mathrm{m}^{2}\right)$ & . & . & 1.09 & $0.98-1.21$ & . & . & 1.11 & $1.05-1.18$ & . & & 1.10 & $1.05-1.16$ \\
\hline \multicolumn{13}{|l|}{ Knee injury ${ }^{b}$} \\
\hline No & 28 & 108 & 1.00 & . & 156 & 291 & 1.00 & 1 & 84 & 399 & 1.00 & . \\
\hline Yes & 25 & 28 & 3.44 & $1.74-6.80$ & 58 & 82 & 1.31 & $0.76-1.90$ & 83 & 110 & 1.51 & $1.05-2.17$ \\
\hline \multicolumn{13}{|l|}{ Physical exercise ${ }^{c}$} \\
\hline None regularly & 34 & 74 & 1.00 & . & 160 & 237 & 1.00 & . & 194 & 311 & 1.00 & . \\
\hline Low & 7 & 20 & 0.61 & $0.40-0.93$ & 15 & 40 & 0.53 & $0.32-0.89$ & 22 & 60 & 0.59 & $0.38-0.91$ \\
\hline High & 4 & 24 & 0.32 & $0.15-0.71$ & 14 & 41 & 0.49 & $0.21-1.12$ & 18 & 65 & 0.41 & $0.20-0.81$ \\
\hline
\end{tabular}

${ }^{a}$ Body mass index at the age of 40 years, continuous variable with the $O R$ expressed per unit $\left(1 \mathrm{~kg} / \mathrm{m}^{2}\right)$.

${ }^{\mathrm{b}}$ Knee injury before 49 years of age.

c Cumulative hours of physical exercise by the age of 49 years divided into two classes according to the mean. 
Table 3. Crude association of severe knee osteoarthritis with the level of occupational exposures before the age of 49 years - logistic regression modeling. ( $\mathrm{OR}=$ odds ratio, $95 \% \mathrm{Cl}=95 \%$ confidence interval)

\begin{tabular}{|c|c|c|c|c|c|c|c|c|c|c|c|c|}
\hline \multirow[t]{2}{*}{ Occupational exposure } & \multicolumn{4}{|c|}{ Men } & \multicolumn{4}{|c|}{ Women } & \multicolumn{4}{|c|}{ All } \\
\hline & $\begin{array}{l}\text { Cases } \\
(\mathrm{N}=55)\end{array}$ & $\begin{array}{c}\text { Referents } \\
(\mathrm{N}=140)\end{array}$ & $\mathrm{OR}$ & $95 \% \mathrm{Cl}$ & $\begin{array}{c}\text { Cases } \\
(N=226)\end{array}$ & $\begin{array}{c}\text { Referents } \\
(\mathrm{N}=384)\end{array}$ & $\mathrm{OR}$ & $95 \% \mathrm{Cl}$ & $\begin{array}{l}\text { Cases } \\
(\mathrm{N}=281)\end{array}$ & $\begin{array}{c}\text { Referents } \\
(\mathrm{N}=524)\end{array}$ & $\mathrm{OR}$ & $95 \% \mathrm{Cl}$ \\
\hline \multicolumn{13}{|l|}{ Physical workload a } \\
\hline Low & 5 & 29 & 1.00 & . & 20 & 58 & 1.00 & . & 25 & 87 & 1.00 & . \\
\hline Medium & 29 & 56 & 3.00 & $1.05-8.57$ & 117 & 206 & 1.64 & $0.94-2.87$ & 146 & 262 & 1.93 & $1.18-3.16$ \\
\hline High & 21 & 55 & 2.21 & $0.75-6.47$ & 87 & 116 & 2.17 & $1.21-3.88$ & 108 & 171 & 2.19 & $1.32-3.64$ \\
\hline \multicolumn{13}{|l|}{ Standing a } \\
\hline Low level & 21 & 33 & 1.00 & . & 42 & 63 & 1.00 & . & 63 & 96 & 1.00 & . \\
\hline Medium level & 9 & 27 & 0.52 & $0.20-1.33$ & 39 & 75 & 0.78 & $0.45-1.35$ & 48 & 102 & 0.68 & $0.42-1.09$ \\
\hline High level & 23 & 78 & 0.46 & $0.22-0.95$ & 141 & 240 & 0.88 & $0.56-1.37$ & 164 & 318 & 0.74 & $0.50-1.07$ \\
\hline \multicolumn{13}{|l|}{ Kneeling or squatting a } \\
\hline None & 14 & 40 & 1.00 & . & 65 & 136 & 1.00 & . & 79 & 176 & 1.00 & . \\
\hline$<2$ hours/day & 14 & 49 & 0.81 & $0.34-1.91$ & 60 & 127 & 0.98 & $0.64-1.51$ & 74 & 176 & 0.95 & $0.65-1.39$ \\
\hline$\geq 2$ hours/day & 25 & 45 & 1.58 & $0.72-3.46$ & 83 & 101 & 1.71 & $1.13-2.60$ & 108 & 146 & 1.69 & $1.17-2.44$ \\
\hline \multicolumn{13}{|l|}{ Climbing a } \\
\hline Low level & 17 & 69 & 1.00 & & 98 & 187 & 1.00 & . & 115 & 256 & 1.00 & . \\
\hline Medium level & 27 & 48 & 2.28 & $1.12-4.64$ & 95 & 151 & 1.20 & $0.84-1.71$ & 122 & 199 & 1.36 & $0.99-1.87$ \\
\hline High level & 11 & 22 & 2.02 & $0.82-4.95$ & 30 & 42 & 1.36 & $0.80-2.31$ & 41 & 64 & 1.47 & $0.94-2.32$ \\
\hline \multicolumn{13}{|l|}{ Walking b } \\
\hline Low level & 16 & 52 & 1.00 & . & 105 & 159 & 1.00 & . & 121 & 211 & 1.00 & . \\
\hline Medium level & 14 & 29 & 1.56 & $0.67-3.66$ & 56 & 108 & 0.78 & $0.52-1.17$ & 70 & 137 & 0.89 & $0.61-1.28$ \\
\hline High level c & 17 & 46 & 1.20 & $0.54-2.64$ & 44 & 70 & 0.95 & $0.60-1.49$ & 61 & 116 & 1.01 & $0.97-1.43$ \\
\hline \multicolumn{13}{|l|}{ Lifting ${ }^{b}$} \\
\hline Low level & 16 & 47 & 1.00 & . & 82 & 146 & 1.00 & . & 98 & 193 & 1.00 & . \\
\hline Medium level & 10 & 22 & 1.33 & $0.52-3.41$ & 49 & 91 & 0.95 & $0.61-1.48$ & 59 & 113 & 1.01 & $0.68-1.51$ \\
\hline High level d & 27 & 67 & 1.18 & $0.57-2.43$ & 83 & 126 & 1.17 & $0.79-1.72$ & 110 & 193 & 1.17 & $0.83-1.64$ \\
\hline \multicolumn{13}{|l|}{ Driving ${ }^{b}$} \\
\hline Low level & 20 & 56 & 1.00 & $\cdot$ & 209 & 351 & 1.00 & . & 229 & 407 & 1.00 & . \\
\hline Medium level & 8 & 36 & 0.62 & $0.24-1.56$ & 10 & 18 & 0.93 & $0.42-2.05$ & 18 & 54 & 0.73 & $0.40-1.33$ \\
\hline High level e & 25 & 46 & 1.52 & $0.75-3.08$ & 6 & 10 & 1.00 & $0.36-2.81$ & 31 & 56 & 1.35 & $0.77-2.37$ \\
\hline
\end{tabular}

${ }^{a}$ Exposure at the age of 49 years. ${ }^{b}$ Cumulative exposure by the age of 49 years. ${ }^{c}$ The highest tertile of the cumulative kilometers of walking.

${ }^{d}$ The highest tertile of the cumulative kilograms of lifted weights. ${ }^{e}$ The highest tertile of the cumulative hours of driving.

First-degree interactions between the different occupational exposures were also studied for their association with the risk of knee OA, but no significant interaction could be observed. However, a significant interaction between BMI and physical workload was found for both the men $(\mathrm{P}=0.03)$ and the women $(\mathrm{P}=0.000)$. For the men and women whose relative weight was normal $(\mathrm{BMI}<25)$, the odds ratio for knee $\mathrm{OA}$ in association with a medium or high workload was 2.65 (95\% CI 0.56-12.5) and 2.24 (95\% CI 0.96-5.22), respectively; whereas, for those who were overweight $(\mathrm{BMI} \geq 25)$, the corresponding odds ratios were 6.12 (95\% CI 1.32-28.2) and 5.48 (95\% CI 2.33-12.9).

When the association between the various trades and the risk of knee OA was considered, all other trades seemed to carry a higher risk than that of professional white-collar workers (table 5). However, none of the gender-specific relative risks reached statistical significance. The highest risk estimates with borderline significance were found for transportation and traffic among the men and for agriculture, fishing, and forestry among the women.

\section{Discussion}

According to this study, a physically heavy workload seems to be detrimental to the knee joint and increase the risk of severe OA. Among the occupational exposures, climbing and kneeling and squatting showed an increased risk for knee OA. On the contrary, standing, especially for men, seemed to exert a protective effect.

The participation rate was higher among the cases than among the referents. The most common reason for nonparticipation among the referents was a problem with locating their telephone numbers. The average 
Table 4. Association of severe knee osteoarthritis with the level of occupational exposure before the age of 49 years, with adjustment for body mass index, knee injury, and physical exercise - logistic regression modeling. (OR = odds ratio, $95 \% \mathrm{Cl}=95 \%$ confidence interval)

\begin{tabular}{|c|c|c|c|c|c|c|}
\hline \multirow[t]{2}{*}{ Occupational exposure } & \multicolumn{2}{|c|}{ Men } & \multicolumn{2}{|c|}{ Women } & \multicolumn{2}{|c|}{ All } \\
\hline & $\mathrm{OR}$ & $95 \% \mathrm{Cl}$ & $\mathrm{OR}$ & $95 \% \mathrm{Cl}$ & OR & $95 \% \mathrm{Cl}$ \\
\hline \multicolumn{7}{|l|}{ Physical workload a } \\
\hline Low & 1.00 & & 1.00 & & 1.00 & \\
\hline Medium & 2.23 & $0.64-7.72$ & 1.60 & $0.83-3.06$ & 1.74 & $0.98-3.09$ \\
\hline High & 1.53 & $0.42-5.56$ & 2.03 & $1.03-3.99$ & 2.02 & $1.11-3.65$ \\
\hline \multicolumn{7}{|l|}{ Standing a } \\
\hline Low level & 1.00 & & 1.00 & & 1.00 & \\
\hline Medium level & 0.57 & $0.18-1.73$ & 0.55 & $0.29-1.04$ & 0.57 & $0.33-0.99$ \\
\hline High level & 0.36 & $0.15-0.90$ & 0.70 & $0.42-1.16$ & 0.62 & $0.40-0.95$ \\
\hline \multicolumn{7}{|l|}{ Kneeling or squatting a } \\
\hline None & 1.00 & & 1.00 & & 1.00 & \\
\hline$<2$ hours/day & 0.58 & $0.21-1.64$ & 0.97 & $0.59-1.59$ & 0.85 & $0.55-1.32$ \\
\hline$\geq 2$ hours/day & 1.68 & $0.66-4.28$ & 1.81 & $1.11-2.95$ & 1.73 & $1.13-2.66$ \\
\hline \multicolumn{7}{|l|}{ Climbing a } \\
\hline Low level & 1.00 & & 1.00 & & 1.00 & \\
\hline Medium level & 3.06 & $1.25-7.46$ & 1.08 & $0.71-1.63$ & 1.31 & $0.91-1.90$ \\
\hline High level & 2.79 & $0.96-8.16$ & 1.50 & $0.81-2.77$ & 1.61 & $0.96-2.71$ \\
\hline \multicolumn{7}{|l|}{ Walking ${ }^{b}$} \\
\hline Low level & 1.00 & & 1.00 & & 1.00 & \\
\hline Medium level & 2.07 & $0.73-5.89$ & 0.89 & $0.56-1.42$ & 1.00 & $0.65-1.53$ \\
\hline High level c & 1.47 & $0.55-3.89$ & 1.06 & $0.64-1.76$ & 1.06 & $0.68-1.64$ \\
\hline \multicolumn{7}{|l|}{ Lifting b } \\
\hline Low level & 1.00 & & 1.00 & & 1.00 & \\
\hline Medium level & 1.35 & $0.57-4.16$ & 0.90 & $0.55-1.50$ & 0.99 & $0.63-1.56$ \\
\hline High level d & 0.92 & $0.50-2.39$ & 1.11 & $0.71-1.75$ & 1.04 & $0.70-1.55$ \\
\hline \multicolumn{7}{|l|}{ Driving ${ }^{b}$} \\
\hline Low level & 1.00 & & 1.00 & & 1.00 & \\
\hline Medium level & 0.81 & $0.28-2.30$ & 1.19 & $0.49-2.85$ & 0.95 & $0.49-1.82$ \\
\hline High level e & 1.35 & $0.59-3.43$ & 0.98 & $0.31-3.10$ & 1.23 & $0.64-2.35$ \\
\hline
\end{tabular}

${ }^{a}$ Exposure at the age of 49 years. ${ }^{b}$ Cumulative exposure by age of 49 years. ${ }^{c}$ The highest tertile of the cumulative kilometers of walking.

d The highest tertile of the cumulative kilograms of lifted weights. e The highest tertile of the cumulative hours of driving.

Table 5. Adjusted relative risk a for severe knee osteoarthritis by occupational category - logistic regression modeling. (OR = odds ratio, $95 \% \mathrm{Cl}=95 \%$ confidence interval)

\begin{tabular}{|c|c|c|c|c|c|c|c|c|c|c|c|c|}
\hline \multirow[t]{2}{*}{ Category } & \multicolumn{4}{|c|}{ Men } & \multicolumn{4}{|c|}{ Women } & \multicolumn{4}{|c|}{ All } \\
\hline & $\begin{array}{l}\text { Cases } \\
(\mathrm{N}=55)\end{array}$ & $\begin{array}{l}\text { Referents } \\
(\mathrm{N}=140)\end{array}$ & $\mathrm{OR}$ & $95 \% \mathrm{Cl}$ & $\begin{array}{c}\text { Cases } \\
(\mathrm{N}=226)\end{array}$ & $\begin{array}{l}\text { Referents } \\
(N=384)\end{array}$ & OR & $95 \% \mathrm{Cl}$ & $\begin{array}{c}\text { Cases } \\
(\mathrm{N}=281)\end{array}$ & $\begin{array}{l}\text { Referents } \\
(N=524)\end{array}$ & $\mathrm{OR}$ & $95 \% \mathrm{Cl}$ \\
\hline Professional & 3 & 21 & 1.00 & . & 17 & 50 & 1.00 & . & 20 & 71 & 1.00 & . \\
\hline Health care \& social work & 2 & - & . & . & 30 & 63 & 1.42 & $0.68-2.97$ & 32 & 63 & 1.65 & $0.83-3.30$ \\
\hline Commerce \& trade & 3 & 10 & 2.71 & $0.30-24.3$ & 18 & 29 & 1.49 & $0.61-3.65$ & 21 & 39 & 1.68 & $0.74-3.83$ \\
\hline Agriculture, forestry \& fishing & 18 & 55 & 1.39 & $0.55-7.56$ & 83 & 116 & 1.63 & $0.83-3.29$ & 101 & 171 & 1.52 & $0.91-3.20$ \\
\hline Transportation \& traffic & 10 & 9 & 5.67 & $0.86-37.3$ & 5 & 8 & 1.95 & $0.51-7.41$ & 15 & 17 & 3.07 & $1.19-7.90$ \\
\hline Manufacturing, construction \& mining & 12 & 38 & 1.59 & $0.27-9.10$ & 27 & 46 & 1.18 & $0.49-2.86$ & 39 & 84 & 1.36 & $0.64-2.89$ \\
\hline Service ${ }^{b}$ & 3 & 5 & 3.99 & $0.41-38.8$ & 38 & 64 & 1.17 & $0.54-2.53$ & 41 & 69 & 1.33 & $0.65-2.74$ \\
\hline
\end{tabular}

a Adjusted for body mass index, knee injury, and physical exercise. ${ }^{\mathrm{b}}$ Includes housewives.

failure rate in finding telephone numbers is about $15 \%$ when Statistics Finland is the provider. The failure may be higher for older persons because some of them already reside in an institution and may thus not have their own telephone. The telephone numbers of the cases were obtained from the Finnish Register of Arthroplasties, in which the telephone numbers had been recently updated. 
Persons with knee problems are often obliged to change jobs. It is possible that they are more likely to change work if their occupation involves, for example, a lot of climbing. This tendency may lead to the "healthy worker effect", which could have caused an underestimation of the association between the exposure and knee OA. A selection effect may explain the nonlinear doseeffect relationship for climbing, walking, and lifting among the men.

In retrospective studies, recall error may lead to bias if it is asymmetric between the cases and referents (30). It is conceivable that, in our study, the cases may have had better recall of their occupational exposures than the referents. This possibility could have led to an overestimation of the effect. A person also tends to judge exposure as being similar to what he or she is currently experiencing (30). In that respect the recall error or our study was probably symmetric between the cases and referents. Bias may also occur if interviewers do not treat the cases and referents equally. In our study, the interviewers did not know who was a case and who was a referent.

The cases were identified through the Finnish Registry of Arthroplasties (27). All joint endoprostheses are reported in its register. During the observation period almost all arthroplasties in the Kuopio Province were carried out in the public health care system; in other words, all residents should have had the same opportunity to receive an endoprosthesis. Referents were drawn from the general population, and therefore some of them had knee OA. The associations detected in this study may have been attenuated.

Women were overrepresented among the cases; less than $20 \%$ of the cases were men. In Finland the predominance of women among the recipients of knee endoprosthesis for knee OA in 1980-1999 was similar to that of our study (31). This ratio between women and men in the occurrence of knee OA is among the highest recorded in the literature (11).

There are only four earlier case-referent studies that have focused on the occupational risk factors of knee OA among women $(14,21-23)$. In two recently published studies, the cases were recruited in the same way as in our study, but the proportion of women was much lower, 60\% (21) and 51\% (22). Differences in the age distributions may explain the discrepancy. After the age of 45 years there is a more pronounced increase in the prevalence of knee OA with age among women than among men (11).

A previous knee injury increased the risk of knee OA by about threefold among the men, but not among the women. In this study a knee injury meant an injury sufficiently severe to require a doctor's consultation. Knee injury is a well-known risk factor for knee OA (7, 11-12). Men may be more prone to severe injuries that can initiate or enhance the degeneration process.

In our study physical exercise during leisure time was negatively associated with the risk of knee OA (32). Moderate recreational exercise may prevent the degeneration process in the knee joint.

The assessment of exposure to physical load at work was based on the subjects' self-estimation. Such a measurement is relatively inaccurate, but it is sufficient and useful for epidemiologic studies (33-36). Lifetime exposure could be calculated for lifting, driving, and walking. To estimate other exposures, only the job held at the age of 49 years was considered to allow for latency. In our study this job reflected well the subject's entire work career because occupational stability was high. An age restriction of exposure has also been used in the earlier case-referent studies $(22,37)$. Whatever the study design, the detection of causal factors for OA necessitates exposure being assessed over a long period before the disease onset.

Self-estimated physical workload proved to be a risk factor for knee OA among both genders. Recall bias may have led to some overestimation of the effect. Nevertheless, the current study provided additional evidence on the deleterious effect of physical workload on the knee joint. The conclusions from earlier studies are not so straightforward. In a recent review, only four of eight studies demonstrated a significantly increased risk of knee OA for subjects with heavy physical work. However, the conclusions in the review were drawn from studies carried out only among men (19). There exist only two previous studies in which an association between physical workload and the risk of knee OA was observed for women $(5,22)$.

Climbing stairs showed a positive association with the risk of knee OA among men. This finding agrees with the results of three earlier studies (21-23). The analysis considering trades and the risk of knee OA indicated that driving carries an increased risk of knee OA among men. In two earlier studies (21-22) driving was explored for its association with the risk of knee OA, but no association was observed.

Standing seemed to provide a protecting effect against knee OA, especially for men. This finding disagrees with the results of a recently published Swedish case-referent study (22). In another study, Schouten and his colleagues (8) detected an increased risk of knee OA among subjects exposed to a medium amount of standing, but not for those with high exposure. The standing position enhances loading of the knee joint. In a recent review it was concluded that joints need loading to maintain the normal state and function of articular cartilage and subchondral bone (38). In our study cumulative lifting proved to have no significant association with the risk of knee OA. This finding agrees with the results of two earlier studies $(8,23)$, but it disagrees 
with the results of two recent studies (21-22). Long-term kneeling and squatting more than 2 hours a day increased the risk of knee OA. A similar result has been reported in four earlier studies $(21-23,39)$.

With respect to the separate job categories, transportation and traffic among men and farming, fishing and forestry among women showed some association with the risk of knee OA. There are only two earlier studies in which the risk of knee OA has been considered across trades $(18,22)$. In these studies an increased risk of knee OA was observed for farmers $(18,22)$, construction workers $(18,22)$, forestry workers (22), firefighters (18), and female cleaners (18).

In conclusion, occupational exposure to physical load on the lower limb increases the risk of knee OA. The associations found for a history of physical workload, climbing, and kneeling and squatting with the risk of knee OA confirm the findings of earlier studies. The protective effect of standing and the detrimental impact of driving on the knee joint are new findings that warrant further studies. Many studies support the wear-andtear hypothesis as a cause of OA. This study provides further evidence of the role of heavy workload in the etiology of knee OA and also emphasizes the importance of cumulative physical stress on the knee joint.

\section{References}

1. Cooper C, McAlindon T, Snow S, Vines K, Young P, Kirwan J, et al. Mechanical and constitutional risk factors for symptomatic knee osteoarthritis: difference between medial and tibiofemoral and patellofemoral disease. J Rheumatol 1994;21:307-13.

2. Cicuttini FM, Spector TD. Genetics of osteoarthritis. Ann Rheum Dis 1996;55:665-76.

3. Spector TD, Cicuttini F, Bakert J, Loughlin J, Hart D. Genetic influences on osteoarthritis in women: a twin study. BMJ 1996;312:940-4.

4. Hartz AJ, Fischer ME, Bril G, Kelber S, Rupley D, Oken B, et al. The association of obesity with joint pain and osteoarthritis in the HANES data. J Chronic Dis 1986;39:311-9.

5. Anderson J, Felson DT. Factors associated with osteoarthritis of the knee in the first national health and nutrition examination survey (HANES I). Am J Epidemiol 1988;128:179-89.

6. Felson DT, Anderson J, Naimark A, Walker AM, Meenan RF. Obesity and knee osteoarthritis. Ann Intern Med 1988;109:18-24.

7. Davis MA, Ettinger WH, Neuhaus JM, Cho SA, Hauck WW. The association of knee injury and obesity with unilateral and bilateral osteoarthritis of the knee. Am J Epidemiol 1989; 130:278-88.

8. Schouten JSAG, van den Ouweland FA, Valkenburg HA. A 12 year follow up study in the general population on prognostic factors of cartilage loss in osteoarthritis of the knee. Ann Rheum Dis 1992;51:932-7.

9. Manninen P, Riihimäki H, Heliövaara M, Mäkelä M. Overweight, gender and knee osteoarthritis. Int J Obesity 1996;
20:595-7.

10. Hart DJ, Doyle DV, Spector TD. Incidence and risk factors for radiographic knee osteoarthritis in middle-aged women: the Chingford study. Arthritis Rheum 1999;42:17-24.

11. Felson DT. Epidemiology of hip and knee osteoarthritis. Epidemiol Rev 1988;10:1-28.

12. Kivimäki J, Riihimäki H, Hänninen $\mathrm{K}$. Knee disorders in carpet and floor layers and painters. Scand J Work Environ Health 1992;18:310-6.

13. Lawrence JS, Molyneux MK, Dingwall-Fordyce I. Rheumatism in foundry workers. Br J Ind Med 1966;23:42-52.

14. Wickström G, Hänninen K, Matsson T, Niskanen T, Riihimäki $\mathrm{H}$, Waris $\mathrm{P}$, et al. Knee degeneration in concrete reinforcement workers. Br J Ind Med 1983;40:216-9.

15. Lindberg H, Montgomery F. Heavy labor and the occurrence of gonarthrosis. Clin Orthop 1987;214:235-6.

16. Kohatsu ND, Schurman DJ. Risk factors for the development of osteoarthritis of the knee. Clin Orthop 1990;261:242-6.

17. Felson DT, Hannan MT, Naimark A, Berkeley J, Gordon G, Wilson PWF, et al. Occupational physical demands, knee bending and knee osteoarthritis: results from the Framingham study. J Rheumatol 1991;18:1587-92.

18. Vingård E, Alfredsson L, Goldie I, Hogstedt C. Occupation and osteoarthrosis of the hip and knee: a register-based cohort study. Int J Epidemiol 1991;20:1025-31

19. Kirkeskov Jensen L, Eenberg W. Occupation as a risk factor for knee disorders. Scand J Work Environ Health 1996;22:165-75.

20. Maetzel A, Mäkelä M, Hawker G, Bombardier C. Osteoarthritis of the hip and knee and mechanical occupational exposure: a systematic overview of the evidence. J Rheumatol 1997;24:1599-607.

21. Coggon D, Croft P, Kellingray S, Barrett D, McLaren M, Cooper C. Occupational physical activities and osteoarthritis of the knee. Arthritis Rheum 2000;43:1443-9.

22. Sandmark H, Hogstedt C, Vingård E. Primary osteoarthritis of the knee in men and women as a result of lifelong physical load from work. Scand J Work Environ Health 2000;26:20 5.

23. Cooper C, McAlindon T, Coggon D, Egger P, Dieppe P. Occupational activity and osteoarthritis of knee. Ann Rheum Dis 1994;53:90-3.

24. Sahlstrom A, Montgomery F. Risk analysis of occupational factors influencing the development of arthrosis of the knee. Eur J Epidemiol 1997;16:675-9.

25. Kellgren JH, Lawrence JS. Rheumatism in miners, II: X-ray study. Br J Ind Med 1952;9:197-207.

26. Kellgren JH, Lawrence JS. Osteoarthritis and disk degeneration in an urban population. Ann Rheum Dis 1958;17:38897.

27. Paavolainen $P$, Hämäläinen $M$, Mustonen H, Slätis P. Registration of arthroplasties in Finland. Acta Orthop Scand 1991; 62 suppl 241:27-30.

28. Frey JH. Survey research by telephone. 2nd ed. Newbury Park (CA): Sage Publication, 1989.

29. Breslow NE, Day NE. Statistical methods in cancer research; vol I (The analysis of case-control studies). Lyon: International Agency for Research on Cancer (IARC), 1980. IARC scientific publications no 82 .

30. Hernberg S. Introduction to occupational epidemiology. Chelsea (MI): Lewis Publishers, 1992.

31. Nevalainen J, Hirvonen A, Pulkkinen P. A study of the outcome of arthroplasty surgery in Finland. Helsinki: Ministry of Social Affairs and Health, 1999. 
32. Manninen $P$, Riihimäki $H$, Heliövaara $M$, Suomalainen $O$. Physical exercise and risk of severe knee osteoarthritis requiring knee arthroplasty. Rheumatology 2001;40:432-7.

33. Wiktorin C, Karlqvist L, Winkel J, Stocholm MUSIC I study group. Validity of self-reported exposures to work postures and manual materials handling. Scand J Work Environ Health 1993;19:208-14.

34. Nordstrom D, Vierkant R, Layde P, Smith M. Comparison of self-reported and expert-observed physical activities at work in a general population. Am J Ind Med 1998;34:29-35.

35. Köster M, Alfredsson L, Michélsen H, Vingård E, Kilbom Å. Retrospective versus original information on physical and psychosocial exposure at work. Scand J Work Environ Health 1999;25:410-4.

36. Torgén M, Winkel J, Alfredsson L, Kilbom Å. Evaluation of questionnaire-based information on previous physical work loads. Scand J Work Environ Health 1999;25:246-54.

37. Vingård E, Alfredsson L, Goldie I, Hogstedt C. Sport and osteoarthritis of the hip: an epidemiologic study. Am J Sports Med 1993;21:195-200.

38. Arokoski J, Jurvelin J, Väätäinen U, Helminen H. Normal and pathological adaptations of articular cartilage to joint loading. Scand J Med Sci Sports 2000;10:186-98.

39. Kirkeskov Jensen L, Mikkelsen S, Lott IP, Eenberg W, Bergmann I, Løgager V. Radiographic knee osteoarthritis in floorlayers and carpenters. Scand J Work Environ Health 2000;26:257-62.

Received for publication: 6 April 2001 